\title{
Adverse Reactions Associated With Studying Persons Recently Exposed to Mass Urban Disaster
}

\author{
Joseph A. Boscarino, PhD, MPH, *† Charles R. Figley, PhD, $\neq$ Richard E. Adams, PhD,* \\ Sandro Galea, MD, DrPH, MPH, $\|$ I Heidi Resnick, PhD, \# Alan R. Fleischman, MD, ** \\ Michael Bucuvalas, PhD, †† and Joel Gold, MDtt
}

\begin{abstract}
This study assesses the psychological consequences of participation in a mental health study among people recently exposed to the September 11 attacks. Using cross-sectional telephone surveys, we interviewed random samples of English-speaking or Spanish-speaking adults living in New York City during the attacks 1 year after this event. Altogether, 2,368 people completed the surveys, including a random sample of 1,173 respondents who received mental health services after the attacks. Results indicated that $15 \%$ of New Yorkers found some of the survey questions stressful, whereas $28 \%$ of those who sought treatment found this to be the case. However, less than $2 \%$ reported being upset at survey completion, and among these persons, only four people consented to speak to the study's mental health consultant. Although the majority of those expressing adverse reactions had sought postdisaster treatment, even among these subjects, only $3 \%$ were still upset at survey completion, and $2 \%$ wanted more information about counseling services. In addition, more than $70 \%$ of participants expressed positive sentiments about survey participation. Predictive models indicated that respondents who met study criteria for posttraumatic stress disorder, depression, or anxiety were more likely to find questions stressful, with people having posttraumatic stress disorder or depression the most likely to be upset and to consent to psychi-
\end{abstract}

*Division of Health and Science Policy, New York Academy of Medicine, New York, NY; †Department of Pediatrics, Mount Sinai School of Medicine, New York, NY; $\ddagger$ School of Social Work, Florida State University, Tallahassee, FL; §Traumatology Institute, Florida State University, Tallahassee, FL; $\|$ Center for Urban Epidemiologic Studies, New York Academy of Medicine, New York, NY; qDivision of Epidemiology, Columbia University Mailman School of Public Health, New York, NY; \#National Crime Victims' Research and Treatment Center, Medical University of South Carolina, Charleston, SC;

**Center for Urban Bioethics, New York Academy of Medicine, New York, NY; ††Schulman, Ronca, \& Bucuvalas Inc., New York, NY; and țBellevue Hospital Center, New York, NY.

Supported in part by a grant from the National Institute of Mental Health (grant \#R01 MH66403 to J. A. B.).

Send reprint requests to Joseph A. Boscarino, PhD, MPH, Division of Health and Science Policy, Room 552, New York Academy of Medicine, 1216 Fifth Avenue, New York, NY 10029-5293.

Copyright (C) 2004 by Lippincott Williams \& Wilkins

ISSN: 0022-3018/04/19208-0515

DOI: $10.1097 / 01 . n m d .0000135476 .20580$ ae atric consultation at completion. We suggest that, with the proper safeguards, research with persons exposed to a resent mass urban disaster generally can be conducted safely and effectively.

Key Words: Surveillance, patient safety, bioethics, iatrogenic, posttraumatic stress disorder, PTSD, psychological trauma, community disaster, terrorism.

( $J$ Nerv Ment Dis 2004;192: 515-524)

$\mathrm{O}$ ver the past decade, Institutional Review Boards have increased surveillance of researchers conducting studies involving human subjects. In part, this heightened vigilance has been a result of high-profile cases in which the study's protocol resulted in the injury or death of research subjects in randomized controlled clinical trials (Figley et al., 1999; Piantadosi, 1997). Although these cases tended to involve clinical trial participants, these adverse outcomes have also led to greater oversight of observational research and examination of the costs versus benefits of participation in such studies (Appelbaum, 1998; Johnson and Benight, 2003; Shore, 1996). Concurrent with this greater oversight has been a sensitivity toward past abuses of informed consent (Collogan et al., 2004) as well as increases in studies focusing on exposure to psychologically traumatic events (Newman et al., 1999; North and Pfefferbaum, 2002), generating heightened concerns about human subject protection.

Researchers have identified several specific issues pertaining to the study of survivors of communitywide traumas (Fleischman and Wood, 2002; Henderson and Jorm, 1990; North et al., 2002; Ruzek and Zatzick, 2000). Recently, it has been suggested that research with populations affected by the September 11 terrorist attacks on the World Trade Center may require additional Institutional Review Board protections to prevent emotional distress among participants, overstudying of subjects, and the general exploitation of a disaster-affected population (Fleischman and Wood, 2002). We label this perspective the adverse research effects model because it is based on the assumption that participants might 
be harmed by study participation. An underlying assumption has been that some direct (and even indirect) victims of community disasters will be too emotionally upset to provide fully informed consent or to anticipate the degree of distress that would accompany their study participation (Fleischman and Wood, 2002). Because informed consent is one of the pillars on which ethical research has been based (Collogan et al., 2004), the inability to provide such consent has been a source of apprehension (Chen et al., 2002). In addition, the potential iatrogenic impact of conducting clinical research among such a population is a reason for increased ethical concern. In summary, although the approach to protect disaster victims after the Oklahoma City bombing recently has been documented (North et al., 2002), there is the belief that conducting research among victims soon after communitywide disasters may be unethical for researchers and harmful for study participants.

Despite these concerns, past research on the negative effects of participation in mental health research and traumarelated studies has been consistent. Although adverse reactions to interview questions have been reported among a small number of research participants, most appear to suffer little or no adverse effect of such participation, especially over the long term (Griffin et al., 2003; Henderson and Jorm, 1990; Jorm et al., 1994; Newman et al., 1999; Parslow et al., 2000; Ruzek and Zatzick, 2000). In their study of women who reported a history of childhood sexual abuse or adult domestic violence, for instance, Newman et al. (1999) reported that $19 \%$ of the women in their study were unexpectedly upset by the sensitive nature of the questions, but that 97\% expressed no regrets over their participation. Similarly, a study of hospitalized victims of motor vehicle accidents or physical assaults found that $89 \%$ of the respondents said that they understood the consent form, $89 \%$ said they would participate in the study again, and $65 \%$ said that they gained something positive from participating (Ruzek and Zatzick, $2000)$. In addition, $80 \%$ or more of the respondents felt that they could have said no to study participation, could have stopped the interview at any time, and could have skipped questions in the survey. In contrast, only $11 \%$ said that they were upset more than they expected (Ruzek and Zatzick, 2000). The one factor most often related to experiencing a negative reaction in a survey was meeting criteria for posttraumatic stress disorder (PTSD) or some other psychological problem such as depression or anxiety (Newman et al., 1999; Parslow et al., 2000).

Even though these findings should reduce the concern about interviewing people who survived a severe trauma, none of these studies examined the issues raised by Fleischman and Wood (2002) for people who have experienced a communitywide disaster. In this study, therefore, we explicitly assessed the possible negative consequences of participation in a mental health study by people who survived such a recent traumatic event. More specifically, we focused on the issues of emotional distress, overstudying, and study perceptions among a large, random sample of adults who lived in New York City (NYC) at the time of the World Trade Center Disaster (WTCD), including a large subsample of those who reported seeking mental health treatment after this event. The WTCD, the largest urban disaster in the United States, resulted in nearly 3,000 deaths and massive destruction in lower Manhattan's business district (Centers for Disease Control, 2002). In our study, we investigated the possible adverse effects of participation in our investigation, controlling for demographic factors, psychological resources, trauma exposures, and current mental health status, all of which would likely increase respondent vulnerability to research participation.

\section{DATA AND METHODS}

Using random-digit dialing, we conducted two concurrent surveys a year after the WTCD. One was a crosssectional household survey of city residents (the general population sample). The other was a cross-sectional household survey of city residents who reported receiving any mental health treatment within a year after the attacks (the treatment oversample). The latter respondents were identified by means of screener questions at the beginning of the survey. English-speaking or Spanish-speaking adults (18 years or older) who were living in New York City at the time of the World Trade Center attacks were eligible respondents for either survey. When interviewers reached a person at a residential telephone number, they obtained area of residence in NYC and verbal consent. Interviewers determined the number of adults in each household and selected one for an interview based on the adult with the most recent birthday. Interviews occurred between October and December 2002. The survey was translated into Spanish and then back translated by bilingual Americans to ensure the linguistic and cultural appropriateness of the survey questions. Trained mental health interviewers using an advanced computerassisted telephone interviewing system and supervised by senior project staff conducted all surveys.

Overall, 2,368 people completed the survey (1,634 for the community sample and 734 for the treatment oversample). Because 439 people in the community sample also received mental health treatment, a total of 1,173 (i.e., $438+$ 734) people received some kind of mental health treatment in the year since the WTCD and were included in the treatment sample. For our study, treatment was defined broadly and included visits to mental health professionals, visits to selfhelp groups (e.g., Alcoholics Anonymous), taking psychotropic medications, seeking professional help on the Internet, using psychoeducational materials provided by health professionals, and receiving group interventions at work sites, community centers, and so forth. Approximately $7 \%$ of the 
interviews were conducted in Spanish. Using survey industry standards (American Association for Public Opinion Research, 2000), the cooperation rate (completed interviews + screen and quota outs/completed interviews + screen and quota outs + refusals) was approximately $63 \%$ for the entire sample. A protocol was in place to provide mental health assistance to all participants who required psychiatric counseling. The duration of the interview was approximately 45 minutes. For the entire sample, a sampling weight was developed to correct for potential selection bias related to the number of telephone numbers and persons per household and for the oversampling of treatment-seeking respondents. This weight allowed us to treat the entire sample as representative of the NYC population. We also developed a sample weight for analyses using the treatment sample separately, which took into account the number of telephone numbers and persons per household for this subgroup. We applied the appropriate weights for the entire sample and the treatment sample analyses, respectively, as discussed below. The Institutional Review Board of the New York Academy of Medicine reviewed and approved the study's protocols.

\section{Study Outcome Variables}

At the end of the interview, respondents were asked a series of questions related to how they felt at survey completion and about their perception of the interview. We also asked whether they had participated in any other WTCD surveys. Based on previous trauma research (Ruzek and Zatzick, 2000), we asked participants whether "any of the survey questions were emotionally upsetting." This question was designed to be sensitive to the possibility of the questions causing emotional harm to the respondent (i.e., it was sensitive, but not specific). If respondents answered yes to this question, they were asked whether they were "still upset" or if they were "feeling okay now." Finally, those respondents who reported that they were still upset at survey completion were offered the following options: 1) general information about available counseling services in the area, 2) a mental health consultant (a licensed clinical psychiatrist) to call them back immediately, and 3) an 800 toll-free number for Project Liberty that they could call at their convenience to receive WTCD-related counseling. Options 1 and 3 were available for those who reported no distress at survey completion as well. For the purposes of the present study, we defined self-report of being upset at survey completion as a potential adverse study effect and consenting to speak to the study's mental health consultant as a likely adverse study effect. In addition, following previous research (Ruzek and Zatzick, 2000), we also inquired about involvement in other WTCD surveys, whether the respondent's perception of the survey was generally positive or negative, and whether the participant thought that "surveys like this one are helpful to New York City in providing and planning future services for those affected by the Trade Center disaster." All the adverse reaction-related survey questions had been developed from previous surveys, had face validity, and were pretested before being used in the current survey.

\section{Predictor Variables}

To predict the potential consequences of participating in our study, we examined a number of key predictor variables, including demographic, exposure, and mental health status variables. Our demographic variables included age, sex, income, marital status, education, and race/ethnicity. Our analyses also assessed one psychological resource (self-esteem) and two stressor variables (exposure to WTCD events and lifetime trauma) that could have affected the respondent's ability to deal with potentially stressful interview questions. Self-esteem was measured by a short version of the Rosenberg Self-Esteem Scale (Rosenberg, 1979). This scale was the sum of five items from the original scale (e.g., "I certainly feel useless at times," "On the whole, I am satisfied with myself"; Cronbach $\alpha=0.73$ ). The Rosenberg Self-Esteem Scale has been widely used in mental health research, and both the reliability and the validity of this measure are considered good (Blascovich and Tomaka, 1991). Our WTCD event exposure measure was the sum of 14 possible events (coded yes/no) that the respondent could have experienced during the attacks (e.g., fear of being killed, friend or relative killed, forced to move from home, lost job as a result of the WTCD, and so forth). This measure was developed from earlier studies (Freedy et al., 1993) and was used in previous WTCD research (Boscarino et al., 2002, 2003, 2004). A second stress measure was based on the sum of 10 lifetime traumatic events the respondent could have experienced other than the WTCD (e.g., being sexually assaulted, being physically attacked, being in a serious accident, and so forth). This lifetime trauma scale also had been used in earlier studies (Freedy et al., 1993) and previous WTCD research (Boscarino et al., 2002, 2003, 2004). For both the WTCD event exposure and traumatic events scales, higher scores indicated greater exposure to these events. In our analyses, both of these scales were collapsed into several categories representing low to high exposure levels.

The survey also assessed the respondent's psychological status. We included these variables because past or current psychological problems could increase the vulnerability of a respondent to the negative consequences of study participation. Using the same approach as the National Comorbidity Survey, we first asked participants if they had received help for any personal or emotional problems during the year after the WTCD from a helping professional (e.g., psychiatrist, counselor, physician, self-help group, and so forth) for "problems with emotions or nerves or use of alcohol or drugs" (Kessler et al., 1997, 1999). Respondents were divided into those who received mental health counseling during this 
time frame and those who did not receive counseling. Second, we determined whether the person met criteria for having a panic attack during the past year. This measure is a modification of the Diagnostic Interview Schedule version (Robins et al., 1999), phrased to assess symptoms that occurred during the past year (American Psychiatric Association, 1994). The presence of four or more symptoms was sufficient to classify the person as having a panic attack if the attack reached its peak within 10 minutes after it started. This scale had also been used in previous WTCD studies and was consistent with the DSM-IV (American Psychiatric Association, 1994; Boscarino et al., 2004).

Our analyses also included measures of PTSD, depression, and anxiety. Our PTSD scale was based on the criteria for DSM-IV and was developed for telephone survey administration and used in the National Women's Study (Resnick et al., 1993) and other general population studies (Kilpatrick et al., 2000). To meet the PTSD criteria in our study, first, a person had to be exposed to a traumatic event (criterion A1) and then had to report experiencing intense feelings of fear, helplessness, or horror (criterion A2). Second, the person had to re-experience the event in one of five ways (criterion B), avoid stimuli associated with the event in three of seven ways (criterion $\mathrm{C}$ ), and have increased arousal in two of five ways (criterion D). Third, the symptoms for criteria B, C, and D had to last 1 month or longer (criterion E). Our PTSD assessment involved evaluation of three sets of experiences. One asked specifically about the WTCD. Another asked about the most stressful traumatic event experienced other than the WTCD. The third asked about any other traumatic event experienced. To have PTSD, the person had to meet the A through $\mathrm{E}$ criteria for one or more of these traumatic events. The Cronbach $\alpha$ for the symptoms used in this scale was 0.90 (Boscarino et al., 2002). In addition, our PTSD scale had a $\kappa$ coefficient with the clinician-administered Structured Clinical Interviews for DSM-III-R of 0.71 for current and 0.77 for lifetime PTSD (Kilpatrick et al., 1998). To date, versions of this PTSD scale have been used in mental health surveys involving more than 10,000 telephone interviews (Acierno et al., 2000; Kilpatrick et al., 2003; Resnick et al., 1993), including several WTCD surveys (Boscarino, Adams, and Figley, 2004; Boscarino et al., 2002, 2003, 2004; Galea et al., 2003). In addition, results obtained with our PTSD scale were consistent with those obtained using the PTSD Checklist (Boscarino et al., 2004). For depression, we adapted the major depressive episode interview scale of the Structured Clinical Interviews for DSM-III-R (Spitzer et al., 1987). More specifically, the survey included 10 mood disturbance symptoms from this scale (e.g., slept more or less than normal, thought about hurting yourself, and so forth). This scale also had been used in previous WTCD surveys (Boscarino et al., 2002, 2003, 2004). Cronbach $\alpha$ for the 10 symptoms from the scale used in the current study was 0.87 .
When the diagnostic results for depression in the past 30 days using our depression scale were compared with those obtained by the Brief Symptom Inventory 18 (BSI-18) depression scale (Derogatis, 2001) among current survey participants, the results were consistent. The BSI-18 depression scale had $73 \%$ sensitivity and $87 \%$ specificity in detecting depression cases as classified by our depression instrument (Boscarino, Adams, and Figley, 2004; Boscarino et al., 2004). In a receiver operating characteristic analysis, a BSI-depression score of $\geq 65$, which was a clinical cutoff for BSIdepression, also optimally predicted depression using our instrument (area under the curve $=0.89$; Boscarino et al., 2004). Overall, our results for both PTSD and depression were consistent with those reported in other mental health population surveys, including the National Comorbidity Survey (Boscarino, Adams, and Figley, 2004). Finally, the presence of anxiety disorder in our survey was assessed using the BSI-18 anxiety scale. This scale is a general measure of psychological anxiety in the past 30 days (Derogatis, 2001). Following the protocol for the scale, we converted this measure into standardized T-scores using a cutoff score of $\geq 65$ to define a current anxiety disorder case. The BSI scale has been widely used in mental health research, and the reliability and validity of this instrument have been documented (Derogatis, 2001).

\section{Statistical Analysis}

We first describe the combined sample, the nontreatment sample, and the treatment sample. Differences between the nontreatment and treatment samples were assessed using $\chi^{2}$ tests. Next, because we expected the treatment sample to exhibit more psychological problems and greater exposure to traumatic events, we planned to limit our adverse reaction analyses to this sample population. We hypothesized that these people were the most likely to experience adverse reactions to the survey questions and were more likely to require mental health counseling. Based on our initial bivariate analyses, we planned to undertake logistic regressions to investigate the unique associations between the predictor variables and our outcome variables related to survey distress. Finally, based on our multivariate analyses, we planned to examine adverse reaction to the survey for those who had met criteria for either PTSD or depression in the past year.

We used the survey estimation (svy) command set in Stata, version 7 (Stata Corp., 2001) to generate frequency distributions, cross-tabulations, $\chi^{2}$ tests, and logistic regression models. This estimation procedure adjusted the data for our sampling design, which included stratification by five city boroughs and the sampling weights described earlier. All $p$-values presented were based on two-tailed tests. 


\section{RESULTS}

We compared the weighted age, sex, race/ethnicity, and geographic distributions obtained in our survey sample with the 2000 US Census statistics for NYC (Boscarino and Adams, 2003); because the distributions were similar, we concluded that our sample was representative of NYC. As expected, inspection of data presented in Table 1 indicates that the treatment population in our study had poorer mental health than the nontreatment population sample. In particular, the former were more likely to have had a panic attack, PTSD, or a depression episode in the past year, and were more likely to have had an episode of anxiety in the past 30 days. The treatment population also was more likely to be exposed to more WTCD events, to have experienced more lifetime traumatic events, and to have had lower self-esteem. In addition, as shown in Table 1, 15\% of NYC adults reported that some of the survey questions were stressful. Among those in the treatment group, $28 \%$ of the respondents stated that they found some questions stressful. On the other hand, less than $2 \%$ of New Yorkers were still upset at survey completion, and only four participants consented to speak to the study's mental health consultant after survey completion. Thus, the majority of those expressing some adverse emotional reaction to the survey were in the treatment population. Nevertheless, even for these respondents, only $3 \%$ were still upset at the end of the survey, $2 \%$ wanted information about counseling services, and only four respondents consented to speak to the study's mental health consultant at completion.

Turning to issues raised by previous researchers, only $3 \%$ of New Yorkers overall and 5\% of the treatment population reported participating in another WTCD survey 1 year postdisaster. In addition, most of New Yorkers expressed positive sentiments about participating in the current survey and the value of such surveys for NYC. Among the treatment population, $76 \%$ reported that participating in the survey was a positive experience, and $82 \%$ reported that these types of surveys would help NYC. There were minor differences between the nontreatment and the treatment populations on these questions, but the difference was significant for reporting that the survey would be beneficial $(p<0.05)$, with the treatment population having a more positive evaluation.

Given the general ethical considerations raised by other investigators, we focused on the treatment population when analyzing models predicting stress during the survey and for being emotionally upset at survey completion. The results of these multivariate logistic analyses (Table 2) revealed that respondents who found some of the survey questions stressful (column 2) tended to be women, those with low self-esteem, those with greater WTCD event exposures, and people who had a panic attack or PTSD in the past year or an episode of anxiety in the past 30 days. Importantly, however, receiving mental health counseling in the previous year was not statistically significant here (Table 2).

Variables predicting being emotionally upset at the end of the survey are shown in Table 2 (column 3 ). Because of the small number of respondents emotionally upset at survey completion, we limited our analyses to five predictor variables that had a statistically significant association with this outcome variable or were of theoretical interest. Only two predictors remained statistically significant in the multivariate model: meeting criteria for PTSD or depression. None of the other variables tested were statistically significant. Table 3 shows the breakdown for the treated sample by our main iatrogenic-related outcomes. As can be seen, whereas nearly $30 \%$ of these persons reported that some survey questions were stressful $(N=335)$, less than $10 \%(N=30)$ of these people reported still being upset at survey completion. Among these persons, 16 indicated that they would like additional mental health information. Furthermore, of these 16 people, only four persons consented to speak to the study's mental health consultant, whereas the remaining 12 persons simply took the toll-free counseling information number to use at their own convenience. To understand better the mental health status of those who reported experiencing some stress during the survey, we stratified the Table 3 results by whether these people had PTSD or depression in the past year, and these findings are displayed in column 4. As can be seen, among the 30 persons reporting being upset at survey completion, a majority (53\% weighted) met the criteria for PTSD or depression. Particularly noteworthy is that among the four persons who consented to counseling, three persons $(62 \%$ weighted) had PTSD or depression. Finally, it also should be noted that after these persons spoke with the study consultant, all cases were resolved without further incident.

\section{DISCUSSION}

This study provided further evidence supporting the relatively modest adverse impact that participating in a study of traumatic events had among respondents. Only $15 \%$ of residents from NYC surveyed after the WTCD reported that some of the interview questions were upsetting. This figure is slightly higher than that reported in some studies (e.g., Henderson and Jorm, 1990; Jorm et al., 1994; Newman et al., 1999), but lower compared with another (e.g., Parslow et al., 2000). Less than $2 \%$ were still upset at the end of the survey. In addition, a large majority felt positive about participation and also thought that such surveys could help NYC provide future services for those affected by the WTCD. It should be noted that our main study outcomes, self-reported stress during or at survey completion, appeared to be quite low. In fact, one could predict that the prevalence of self-reported stress among college students after a major examination would likely be higher. Finally, our results suggested that NYC residents did not appear to be unduly burdened by 
TABLE 1. Characteristics of combined, nontreatment, and treatment sample populations

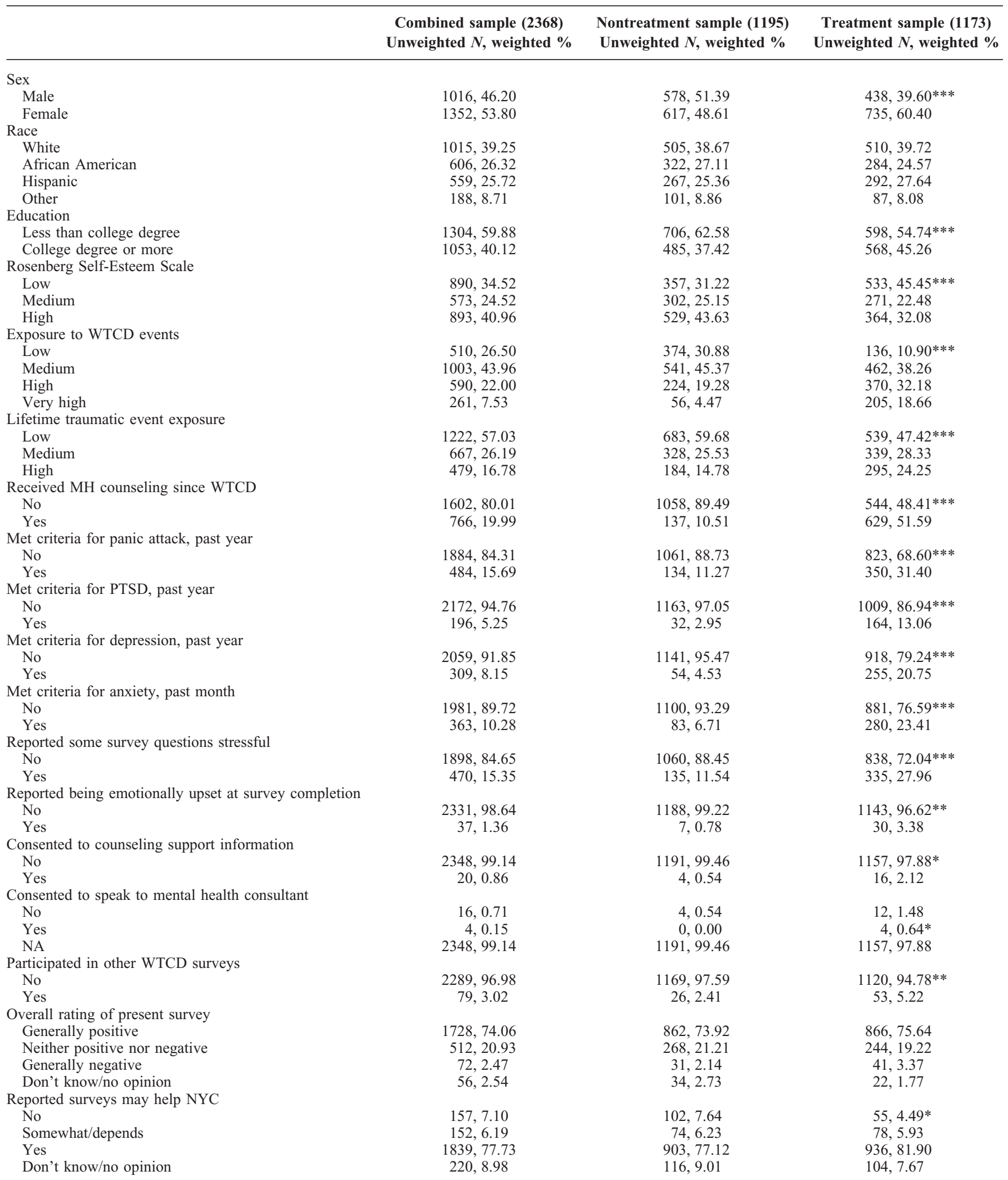

Difference between nontreatment and treatment samples: ${ }^{*} p<.05$; ${ }^{*} p<.01 ;{ }^{* * *} p<.001$, based on $\chi^{2}$ test. 
TABLE 2. Predictors related to reports of any stressful survey questions and being upset at survey completion among treatment sample population ${ }^{\mathrm{a}}$

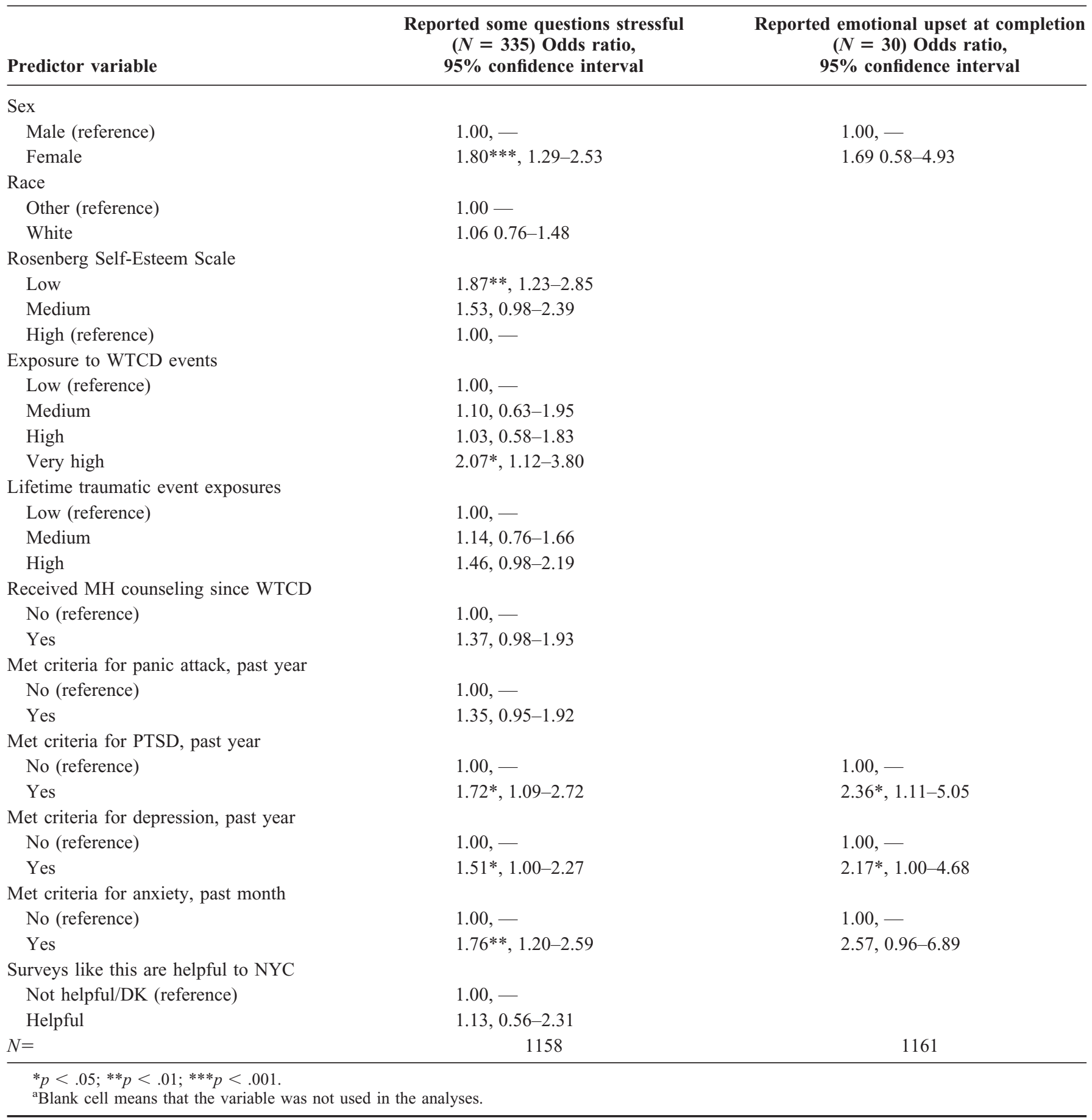

researchers, because only 3\% of New Yorkers had participated in another WTCD survey 1 year postdisaster. We conclude, therefore, that there is little support for the adverse research effects or for the oversurveying hypotheses in NYC after the WTCD.
These relatively positive findings held even when we focused on the treatment subsample. That is, few of these treatment seekers were upset at the conclusion of the survey, whereas most felt positive about study participation. In addition, only $5 \%$ of the latter people had participated in other 
TABLE 3. Outcomes among treatment sample participants who reported some interview questions stressful $(N=1173)$

\section{Outcome variables}

Reported some questions stressful

Reported emotional upset at completion

Consented to information on counseling services

Consented to speak to consultant at completion

Did not consent to consultation, but accepted toll-free 800 number
Percentage of treated sample
Number of patients, unweighted

$\begin{array}{rr}27.96 & 335 \\ 3.38 & 30 \\ 2.12 & 16 \\ 0.64 & 4 \\ 1.48 & 12\end{array}$

Percentage of patients

with PTSD or

depression

(unweighted $N$ )

41.74 (144)

$52.60(17)$

$52.58(9)$

$61.54(3)$

$48.68(6)$
WTCD studies. Thus, even for this more vulnerable population, there was little support for the hypothesis that survivors of a communitywide trauma were negatively affected by study participation. In fact, participation actually seemed to be associated with positive feelings about the study. As seen in Table 2, mental health service use after the attacks was positively related to poorer mental status and greater exposure to lifetime trauma, exposure to recent stressful life events, and greater exposure to WTCD events, so this treatment population was clearly a higher-risk group.

In attempting to explain the positive effects of participating in trauma studies, some researchers have used inhibition theory (Pennebaker and Beall, 1986; Pennebaker et al., 1990; Smyth et al., 1999). The central argument of this theory is that inhibiting thoughts, feelings, and behavior requires physiological effort. Within the context of this model, inhibiting discussion and thought about traumatic events over a long period is believed to be physiologically stressful and may result in increased vulnerability to stress-related physical disorders. Discussing these events in written or verbal context is believed to lower psychological distress and to reduce the likelihood of future negative health outcomes. In other words, disclosing past traumas may be not harmful but beneficial to the person. For example, research on trauma disclosure among patients with asthma or rheumatoid arthritis suggests that writing about the most stressful event of their lives resulted in clinical improvement in their symptoms when evaluated by physicians 2 weeks, 2 months, and 4 months after the writing exercise (Smyth et al., 1999). Another study among college students found that those who disclosed more severe traumas had fewer physical health symptoms in the months after the study (Greenberg and Stone, 1992). However, more research is needed to evaluate this approach, because there are psychobiological reasons to suspect that strictly cognitive approaches to emotionally charged events may be limited (Boscarino, 1995, 2004; Shean, 2001).

Our analyses suggest, however, that researchers still need to be careful when interviewing victims exposed to psychological trauma. Similar to the results of other studies
(Newman et al., 1999; Parslow et al., 2000), people who met criteria for PTSD or depression were more likely to be upset at the end of the interview, to consent to receiving information about counseling services, and to consent to speak to a mental health consultant at survey completion. Thus, attention should be given to respondents who screen positive for psychological problems in a trauma study. These persons generally should be provided with sufficient information on how to receive services, should they perceive the need after study participation. In addition, as Fleischman and Wood (2002) have suggested, the informed consent form should contain a statement that participation in studies of responses to potentially traumatic events can be stressful for some people, but that many find this to be a positive experience.

The results of this study need to be viewed within the context of its limitations and strengths. First, the survey may have missed people who left NYC because of the attacks. However, the impact of this is likely minor, because more than $90 \%$ of the persons surveyed were living in the same place they were at the time of the WTCD. Second, we omitted people without a telephone and those who did not speak either English or Spanish. Given that the sample matched the 2000 Census for NYC (Boscarino, Adams, and Figley, 2004), however, the absence of these households did not appear to have introduced any significant demographic bias overall. Nevertheless, we are limited in generalizing to other ethnic/ language groups in NYC. To date, little research has focused on how the WTCD affected immigrant communities and the wide variety of ethnic groups living in NYC. Participation may have had more deleterious effects on people within such groups. Third, the data are cross-sectional and cannot be used to test causal relationships. It is possible that other factors may be related to reactions to our survey questions. Fourth, our survey was conducted 1 year postdisaster, and the results may have been different if we surveyed more recently after the attacks, although NYC residents were on a heightened state of alert during the 1-year WTCD anniversary when we conducted our survey (e.g., NYC was under a high terrorism alert [Code Orange] at the time of the survey.) Fifth, although 
we focused our analyses on those who sought some kind of treatment, and these persons tended to have more psychopathology and potential trauma exposures (Table 2), this group should not be considered the highest exposure/risk group as a whole, compared with those who were at the World Trade Center site at the time of the attack.

These limitations should not overshadow the major strengths of the study. Some of these included the use of large random samples representative of NYC, the assessment of mental status using standard scales, and the focus on a specific event that meets the criteria for communitywide disaster, since the WTCD was one of the most deadly disasters in US history. Although we found little evidence to support the notion that participation in community disaster research results in adverse psychological reactions, it is possible that other negative consequences of participation may emerge. Thus, continuing investigation and respondent protections clearly seem warranted (Collogan et al., 2004). As Fleischman and Wood (2002) noted, "Investigators must ensure that studies are designed to minimize harms and risks to the subjects, that subjects are given the opportunity to provide voluntary and uncoerced decisions about participation, and that participation is not overly burdensome to specific individuals or populations" (p. 320). Study participants give researchers their time and energy so that we can obtain information to improve quality of life and patient care. We need to make sure that we do not abuse this privilege. On the other hand, policies restricting trauma research based on presumed iatrogenic effects of research appear flawed. Overcautious policies may prevent research leading to greater understanding of who is most vulnerable after traumatic event exposures and what should be done (or avoided) to facilitate resiliency and recovery from these catastrophic human events.

\section{ACKNOWLEDGMENTS}

Versions of this article were presented at the 111th Annual Meeting of the American Psychological Association, Toronto, Canada, August 2003, and at the 36th Annual Meeting of the Society for Epidemiologic Research, Atlanta, GA, June 2003.

\section{REFERENCES}

Acierno R, Kilpatrick DG, Resnick H, Saunders B, De Arellano M, Best C (2000) Assault, PTSD, family substance use and depression as risk factors for cigarette use in youth: Findings from the National Survey of Adolescents. J Trauma Stress. 13:381-396.

American Association for Public Opinion Research (2000) Standard Definitions: Final Dispositions of Case Codes and Outcomes Rates for Surveys. Ann Arbor, MI: American Association for Public Opinion Research.

American Psychiatric Association (1994) Diagnostic and Statistical Manual of Mental Disorders (4th ed). Washington DC: American Psychiatric Association.

Appelbaum PS (1998) Missing the boat: Competence and consent in psychiatric research. Am J Psychiatry. 155:1486-1488.
Blascovich J, Tomaka J (1991) Measure of self-esteem. In JP Robinson, PR Shaver, LS Wrightsman (Eds), Measures of Personality and Social Psychological Attitudes (pp 115-160). New York: Academic Press.

Boscarino JA (2004) Posttraumatic stress and physical health: Results from clinical and epidemiologic studies. Ann N Y Acad Sci. (in press).

Boscarino JA (1995) Post-traumatic stress and associated disorders among Vietnam veterans: The significance of combat exposure and social support. J Trauma Stress. 8:317-336.

Boscarino JA, Adams RE, Figley CR (2004) Mental health service use 1 year after the World Trade Center disaster: Implications for medical care. Gen Hosp Psych. 26:2004 (in press).

Boscarino JA, Galea S, Adams RE, Ahern J, Resnick H, Vlahov D (2004) Mental health services and psychiatric medication use following the terrorist attacks in New York City. Psychiatr Serv. 55:274-283.

Boscarino JA, Galea S, Ahern J, Resnick H, Vlahov D (2003) Psychiatric medication use among Manhattan residents following the World Trade Center disaster. J Trauma Stress. 16:301-306.

Boscarino JA, Galea S, Ahern J, Resnick H, Vlahov D (2002) Utilization of mental health services following the September 11th terrorist attacks in Manhattan, New York City. Int J Emerg Ment Health. 4:143-155.

Centers for Disease Control (2002) Deaths in World Trade Center terrorist attacks-New York City, 2001. MMWR Morb Mortal Wkly Rep. 51(September 11, Special Issue):16-18.

Chen DT, Miller FG, Rosenstein DL (2002) Enrolling decisionally impaired adults in clinical research. Med Care. 40(suppl):V20-V29.

Collogan LK, Dolan-Sewell R, Tuma F, Borja S, Fleischman AR (2004) Ethical issues pertaining to research in the aftermath of disaster. $J$ Trauma Stress. 17:(in press).

Derogatis LR (2001) Brief Symptom Inventory 18 (BSI-18) Manual. Minnetonka, MN: NCS Assessments.

Figley CR, Carbondale JL, Boscarino JA, Chang J (1999) A clinical demonstration model for assessing the effectiveness of therapeutic interventions: An expanded clinical trials methodology. Int J Emerg Ment Health. 3:155-164.

Freedy JR, Kilpatrick DG, Resnick HS (1993) Natural disasters and mental health: Theory, assessment and intervention. J Soc Behav Pers. 8(Special Issue: Handbook of Post-Disaster Interventions):49-103.

Fleischman AR, Wood EB (2002) Ethical issues in research involving victims of terror. J Urban Health. 79:315-321.

Galea S, Vlahov D, Resnick H, Ahern J, Susser E, Gold J, Bucuvalas M, Kilpatrick D (2003) Trends in probable posttraumatic stress in New York City after the September 11 terrorist attacks. Am J Epidemiol. 158:514524.

Greenberg MA, Stone AA (1992) Emotional disclosure about trauma and its relation to health: Effects of previous disclosure and trauma severity. $J$ Pers Soc Psychol. 63:75-84.

Griffin MG, Resick PA, Waldrop AE, Mechanic MB (2003) Participation in trauma research: Is there evidence of harm? J Trauma Stress. 16:221-227.

Henderson AS, Jorm AF (1990) Do mental health surveys disturb? Psychol Med. 20:721-724.

Johnson LE, Benight CC (2003) Effects of trauma-focused research on recent domestic violence survivors. J Trauma Stress. 16:567-571.

Jorm AF, Henderson AS, Scott R, Mackinnon AJ, Korten AE, Christensen H (1994) Do mental health surveys disturb? Further evidence. Psychol Med. 24:233-237.

Kessler RC, Frank RG, Edlund M, Katz SJ, Lin E, Leaf P (1997) Differences in the use of psychiatric outpatient services between the United States and Ontario. N Engl J Med. 336:551-557.

Kessler RC, Zhao S, Katz SJ, Kouzis AC, Frank RG, Edlund M, Leaf P (1999) Past-year use of outpatient services for psychiatric problems in the National Comorbidity Survey. Am J Psychiatry. 156:115-123.

Kilpatrick DG, Acierno R, Saunders B, Resnick HS, Best CL, Schnurr PP (2000) Risk factors for adolescent substance abuse and dependence: Data from a national survey. J Consul Clin Psychol. 68:19-30.

Kilpatrick DG, Resnick HS, Freedy JR, Pelcovitz D, Resick P, Roth S, van der Kolk B (1998) The posttraumatic stress disorder field trial: Evaluation of the PTSD construct-Criteria A through E. In T Widiger, A Frances, H Pincus, R Ross, M First, W Davis, and M Kline (Eds), DSM-IV Sourcebook (Vol 4, pp 803-844). Washington DC: American Psychiatric Association Press. 
Kilpatrick DG, Ruggiero KJ, Acierno R, Saunders BE, Resnick HS, Best CL (2003) Violence and risk of PTSD, major depression, substance abuse/ dependence and comorbidity: results from the national survey of adolescents. J Consult Clin Psychol. 71:692-700.

Newman E, Walker EA, Gefland A (1999) Assessing the ethical costs and benefits of trauma-focused research. Gen Hosp Psychiatry. 21:187-196.

North CS, Pfefferbaum B, Tucker P (2002) Ethical and methodological issues in academic mental health research in populations affected by disasters: The Oklahoma City experience relevant to September 11, 2001. CNS Spectr. 7:580-584.

North CS, Pfefferbaum B (2002) Research on the mental health effects of terrorism. JAMA. 288:633-636.

Parslow RA, Jorm AF, O'Tolle BI, Marshall RP, Grayson DA (2000) Distress experienced by participants during an epidemiological survey of posttraumatic stress disorder. J Trauma Stress. 13:465-471.

Pennebaker JW, Beall S (1986) Confronting a traumatic event: Toward an understanding of inhibition and disease. J Abnorm Psychol. 95:274-281.

Pennebaker JW, Colde M, Sharp LK (1990) Accelerating the coping process. J Pers Soc Psychol. 58:528-537.

Piantadosi S (1997) Clinical Trials: A Methodological Perspective. New York: John Wiley and Sons.

Resnick HS, Kilpatrick DG, Dansky BS, Saunders BE, Best C (1993)
Prevalence of civilian trauma and posttraumatic stress disorder in a representative national sample of women. J Consult Clin Psychol. 61: 984-991.

Rosenberg M (1979) Conceiving the Self. New York: Basic Books.

Robins LN, Cottler LB, Bucholz KK, Compton WM, North CS, Rourke KM (1999) Diagnostic Interview Schedule for DSM-IV. St. Louis, MO: Washington University School of Medicine, Department of Psychiatry (Revised January 9, 2002).

Ruzek JI, Zatzick DF (2000) Ethical considerations in research participation among acutely injured trauma survivors: An empirical investigation. Gen Hosp Psychiatry. 22:27-36.

Shean C (2001) A critical look at the assumptions of cognitive therapy. Psychiatry. 64:158-164.

Shore D (1996) Ethical principles and informed consent: An NIMH perspective. Psychopharmacol Bull. 32:7-10.

Smyth JM, Stone AA, Hurewitz A, Kaell A (1999) Effects of writing about stress experiences on symptom reduction in patients with asthma or rheumatoid arthritis: A controlled trial. JAMA. 281:1304-1309.

Spitzer RL, Williams JB, Gibbon M (1987) Structured Clinical Interview for DSM-III-R-Non-Patient Version. New York: Biometrics Research Department, New York State Psychiatric Institute.

Stata Corp (2001) Stata (Version 7.0). College Station, TX: Stata Corp. 